\title{
Influence of post-rumen supply of nutrients on rumen digesta load and voluntary intake of a roughage by sheep
}

\author{
BY S. G. GHERARDI* AND J. L. BLACK \\ CSIRO. Division of Animal Production, Box 239, Blacktown, New South Wales 2148, Australia
}

(Received 30 December 1988 - Accepted 3 July 1989)

\begin{abstract}
The effect of post-rumen supply of nutrients on the rumen digesta load and voluntary consumption of roughage by Border Leicester $\times$ Merino ram lambs was investigated. A chopped wheaten hay was offered to the ram lambs ( $n$ 24), whose nutrient intake was altered by infusing into the abomasum a liquid supplement, containing reconstituted cow's milk, sodium caseinate, minerals and vitamins, for a period of at least $30 \mathrm{~d}$. Either two or three lambs were allocated by live weight to each of ten rates of nutrient supplementation. The lambs were slaughtered at a target live weight of $31 \mathrm{~kg}$. Voluntary intake of hay was estimated over the last $7 \mathrm{~d}$ of feeding. The amounts of digesta and organic matter $(O M)$ in the rumen were measured by emptying after slaughter. The particle size distribution of the digesta was measured by wet sieving and the fractional outflow rate of particulate matter by reference to the marker lignin. Growth rate of the lambs increased linearly as total energy infused increased. The linear increase in growth rate indicated that roughage was not substituted for infused nutrients on a direct energy basis. OM intake from hay declined linearly as the amount of nutrients infused increased. The decline in intake was associated with a decline in both total digesta and the amount of rumen OM. Both the fractional digestion rate of $\mathrm{OM}$ and the fractional outflow rate of particulate matter from the rumen were unaffected by the amount of nutrients infused. The results indicated that the rumen digesta load of young sheep fed on a single roughage is directly related to their energy deficit, that is the difference between the capacity of the animals to use energy and the energy available to them for metabolism.
\end{abstract}

Rumen digesta load: Voluntary intake: Sheep

Voluntary feed intake by sheep may be limited by the potential of the animal to use nutrients, the amount of digesta that can accumulate in the rumen, the rate of removal of digesta from the rumen, the palatability of the diet or the time available for eating and ruminating activities (Black, 1984; Weston, 1985). Although each of these factors is important, there is little quantitative information on the determinants of rumen digesta load, which has been predicted to affect markedly the voluntary intake of roughage by sheep (Black et al. 1982).

Weston (1984) observed that the amount of rumen digesta, i.e. the load, was inversely related to the net energy intake in young sheep fed on roughage diets that failed to meet their capacity to use nutrients. He postulated that, with such diets, rumen digesta load may be related to the energy deficit of the animal; energy deficit being defined as the difference between the capacity of the animal to use energy and the energy available for metabolism. However, the diets used by Weston (1984) varied widely in chemical and physical properties that could also have affected rumen digesta load, for example digestibility, palatability and packing density. More quantitative information is required for the development of accurate relationships to define the effect of changes in energy deficit per se on rumen digesta load (Black, 1984).

Accordingly, an experiment was conducted in which a single roughage was offered to

* Present address : Division of Animal Production, Department of Agriculture, Baron-Hay Court, South Perth, Western Australia 6151, Australia. 
young sheep and their energy balance was altered by infusing into the abomasum a nutrient mixture containing reconstituted cow's milk, sodium caseinate, minerals and vitamins. A preliminary report on part of the study has been published (Gherardi et al. 1985).

\section{EXPERIMENTAL}

\section{Sheep and management}

Twenty four Border Leicester $\times$ Merino ram lambs of approximately 4-6 weeks of age (10-15 kg) were fitted with an abomasal catheter by Witzel's gastrostomy technique (Black \& Griffiths, 1975). The lambs were vaccinated against enterotoxaemia, blackleg, black disease, malignant oedema and tetanus (Vaxall 5; Websters, Sydney), treated with Sulphamethazine (Coopers Animal Health, Sydney) to control intestinal coccidia and with Mansonil (Bayer Australia Ltd) to control tapeworm (Moniezia expansa). The lambs were treated as a group and were offered lucerne (Medicago sativa) hay ad lib. The live weights of the lambs were measured twice weekly.

When the lambs reached their pre-experimental initial target live weights, they were transferred to metabolism cages in a room in which there was continuous lighting and the temperature was maintained between 19 and $23^{\circ}$. The lambs were drenched with Rametin (Bayer) and Ranide (Merck Sharp \& Dohme, Sydney) to control helminths and liverfluke (Fasciola hepatica). Water was freely available at all times. At the target live weight of $31 \mathrm{~kg}$, the lambs were killed with an intravenous injection of Valabarb (Syntex Agribusiness, Sydney); all lambs were slaughtered at the same time relative to feeding. The gastrointestinal (GI) tract was removed from each animal and subdivided into reticulorumen (rumen), omasum, abomasum, small intestine, caecum/proximal colon and distal colon. Any omental fat was removed from each organ before weighing. The contents were then removed and weighed. The empty organ was washed with water, dried with paper towels and weighed. The value for the contents of each organ was derived by averaging the direct and indirect estimates of total contents. Samples were stored at $-10^{\circ}$ until analysed.

\section{Basal diet}

The lambs were offered a wheaten hay cut to $21 \mathrm{~mm}$ lengths using a modified chaff cutter. The chopped hay was passed through a mechanical sieve (California Pellet Mills, San Francisco, USA) which removed the majority of hay particles that were longer or shorter than $21 \mathrm{~mm}$. It was then mixed in $100 \mathrm{~kg}$ lots and sprayed with a solution of urea, sodium sulphate and cobalt chloride to provide $(\mathrm{g} / \mathrm{kg}$ dry matter $(\mathrm{DM}))$ : nitrogen $13 \cdot 0$, sulphur 0.92 and cobalt 0.0001 (Agricultural Research Council, 1965, 1980; Neutze, 1985). The unsprayed basal diet contained $(\mathrm{g} / \mathrm{kg} \mathrm{DM}): 940$ organic matter $(\mathrm{OM}), 697$ cell wall organic matter (CWOM), $90 \cdot 7$ acid-detergent lignin (ADL) and $4 \cdot 18 \mathrm{~N}$.

The lambs were introduced to the hay over a period of $5 \mathrm{~d}$, by increasing in equal increments each day the proportion of wheaten hay and reducing the proportion of lucerne hay. The wheaten hay was offered to the lambs from automatic feeders which presented a fresh bucket of feed every $3 \mathrm{~h}$. Residues were collected daily and the amount of feed offered was $20 \%$ in excess of the previous day's consumption. The feed was distributed equally amongst the eight buckets. Voluntary intake and the digestibility of the hay were estimated over the last $7 \mathrm{~d}$ of feeding.

\section{Experimental design}

Either two or three lambs were allocated to each of ten treatments which commenced once they reached the pre-experimental initial target live weight (Table 1). The initial target 
Table 1. A summary of the energy supplied in a liquid supplement per unit metabolic live weight (live weight ${ }^{0.75}, M L W$ ), predicted growth rates and pre-experimental target live weight for the lambs

\begin{tabular}{|c|c|c|c|c|c|c|c|}
\hline \multirow[b]{2}{*}{ Treatment } & \multirow{2}{*}{$\begin{array}{l}\text { No. of } \\
\text { lambs }\end{array}$} & \multicolumn{3}{|c|}{$\begin{array}{l}\text { Gross energy infused } \\
\text { (MJ/d per kg MLW) }\end{array}$} & \multicolumn{2}{|c|}{$\begin{array}{l}\text { Predicted } \\
\text { growth rate }\end{array}$} & \multirow{2}{*}{$\begin{array}{l}\text { Pre-experimental } \\
\text { target live wt }(\mathrm{kg})\end{array}$} \\
\hline & & Milk* & Caseinate $\dagger$ & Total & $\mathrm{g} / \mathrm{d}$ & $\mathrm{kg} / 28 \mathrm{~d}$ & \\
\hline 1 & 3 & 0 & 0.08 & 0.08 & 0 & 0 & 31.0 \\
\hline 2 & 3 & $0 \cdot 10$ & $0-08$ & 0.18 & 60 & $1 \cdot 7$ & $29 \cdot 3$ \\
\hline 3 & 2 & 0.20 & 0.08 & 0.28 & 110 & $3 \cdot 1$ & 27.9 \\
\hline 4 & 2 & $0 \cdot 30$ & 0.08 & $0 \cdot 38$ & 164 & $4 \cdot 6$ & 26.4 \\
\hline 5 & 2 & 0.41 & 0.08 & 0.49 & 199 & 5.6 & 25.4 \\
\hline 6 & 3 & 0.51 & 0.08 & 0.59 & 234 & 6.6 & $24 \cdot 4$ \\
\hline 7 & 3 & 0.61 & $0-08$ & 0.69 & 268 & 7.5 & 23.5 \\
\hline 8 & 2 & 0.81 & 0.08 & 0.89 & 333 & $9 \cdot 3$ & 21.7 \\
\hline 9 & 2 & 0.92 & 0.08 & 1.00 & 364 & 10.2 & 208 \\
\hline 10 & 2 & 1.02 & 0.08 & $1 \cdot 10$ & 390 & 109 & $20-1$ \\
\hline
\end{tabular}

* Gross energy of milk 23.4 MJ/kg dry matter (Colebrook \& Black, 1981).

$\dagger$ Gross energy of caseinate $22.8 \mathrm{MJ} / \mathrm{kg}$ dry matter (N. McC. Graham, personal communication).

live weights were estimated using a computer-simulation model (Black, 1984) to allow for an infusion period of $28 \mathrm{~d}$ before the lambs reached the target live weight of $31 \mathrm{~kg}$.

A liquid supplement of reconstituted full cream cow's milk, sodium caseinate, vitamins and minerals was infused into the abomasum of each lamb using a turret head peristaltic pump. The gross energy (GE) content of the liquid supplement was altered by varying the amount of reconstituted full cream milk in the diet (Table 1). To ensure that essential nutrients were not limiting the intake of the wheaten hay, caseinate equivalent to $1.39 \mathrm{~g}$ $\mathrm{N} /$ unit GE intake (MJ/d per kg live weight ${ }^{0.75}$ (metabolic live weight; MLW)) (Black \& Griffiths, 1975), and a complete vitamin and mineral mix (Colebrook \& Black, 1981) were added to the liquid supplement. The supplement was infused at a rate of $3.3 \mathrm{litres} / \mathrm{d}$. The animals were introduced to the liquid supplement over a period of $10 \mathrm{~d}$, by increasing the proportion of milk in equal daily increments. It was assumed that the liquid supplement was totally digested in the small intestine.

\section{Eating and ruminating behaviour}

A record of the eating and ruminating behaviour for each lamb was conducted for a period of $24 \mathrm{~h}$ during the last $7 \mathrm{~d}$ of feeding. Jaw movements were recorded using a Korotkoff sound microphone (Narco Bio-Systems, Houston, USA) which was fixed to the jaw of the lamb with a medical adhesive (Dow Corning, Sydney). The signals from the microphone were relayed to a Physiograph Mk III recorder (Narco Bio-Systems) with a chart output set at a speed of $0.5 \mathrm{~mm} / \mathrm{s}$. The time spent eating and ruminating as well as the number of boli per rumination cycle were assessed from the pattern of jaw movements.

\section{Analytical procedures}

Samples of feed offered, feed residues, faeces and rumen contents were analysed for DM content by drying to a constant weight at $105^{\circ}$ and for OM content by ashing the samples at $550^{\circ}$ for $3 \mathrm{~h}$ (Faichney \& White, 1983). All the samples were analysed for CWOM and ADL by using the filtrex method described by Faichney \& White (1983). A sample of the 
unsprayed hay offered was analysed for $\mathrm{N}$ content by using a Kjel-Foss Automatic Nitrogen Analyser (Foss Electric, Copenhagen, Denmark).

The distribution of digesta particle size in the rumen was determined by the wet sieving method described by Poppi et al. (1980).

\section{Calculations}

ADL was used as the particulate matter marker in the rumen. The fractional outflow rate of particulate matter from the rumen was calculated from the equation of Faichney (1980). It was assumed that the faecal output of ADL provided an accurate estimate of its abomasal flow, as there is no significant disappearance of ADL in grass hays postruminally (Neilsen \& Richards, 1978).

The fractional digestion rate of OM in the rumen $\left(k_{d}\right)$ was derived by comparing $k_{d}$ values calculated as:

$$
k_{d}(/ d)=\frac{\mathrm{OM} \text { intake }(\mathrm{g} / \mathrm{d})}{\text { rumen OM }(\mathrm{g})}-\frac{\text { faecal } \operatorname{ADL}(\mathrm{g} / \mathrm{d})}{\text { rumen } \operatorname{ADL}(\mathrm{g})} .
$$

The growth rate for each lamb was determined from the regression of the observed live weight for each lamb $v$. time for the last $14 \mathrm{~d}$ of each infusion period. The live weight of each lamb was measured $( \pm 0.1 \mathrm{~kg})$ at approximately the same time relative to feeding on every alternate day.

The estimated metabolizable energy (ME) and net energy (NE) intake of the lambs were calculated by partitioning digestion between the rumen and the post-rumen GI tract based on the assumptions of Black (1971). It was assumed that the fleece weight of the lambs at the time of slaughter was $2.0 \mathrm{~kg}$, based on information for animals of similar genotype, live weight and age (R. H. Weston, unpublished results).

\section{Statistical analysis}

Statistical significance of the experimental values was established by analysis of variance. The statistical package GENSTAT was used to perform analyses of variance from which linear, quadratic and cubic models relating total energy infused and the values collected for each animal were compared. Significant linear relationships were fitted in all cases.

\section{RESULTS}

Growth rates

The growth rate of the lambs increased linearly with the amount of nutrients infused, when expressed as the total energy infused (MJ/d per $\mathrm{kg} \mathrm{MLW)} \mathrm{(Fig.} \mathrm{1(a)).} \mathrm{Lambs} \mathrm{offered}$ wheaten hay and infused with caseinate alone (treatment 1) grew at $34 \mathrm{~g} / \mathrm{d}$.

\section{Intake and rumen contents}

OM intake from the hay declined as the quantity of nutrients infused increased (Fig. $1(b)$ ). The decline in intake was paralleled by a decline in both the total amount of digesta (Fig. $1(c)$ ) and OM present (Fig. $1(d)$ ) in the rumen expressed per unit empty body-weight (EBW). Similarly, rumen OM content as a proportion of DM decreased as the quantity of nutrients infused increased (Table 2 ). The relationship was:

$$
Y=90 \cdot 60(\mathrm{SE} 0 \cdot 43)-2 \cdot 356(\operatorname{SE} 0 \cdot 680) X, \quad r^{2} 0 \cdot 35,
$$

where $Y$ is rumen OM content as a proportion of DM (\%) and $X$ is the total energy infused (MJ/d per $\mathrm{kg} \mathrm{MLW).}$ 

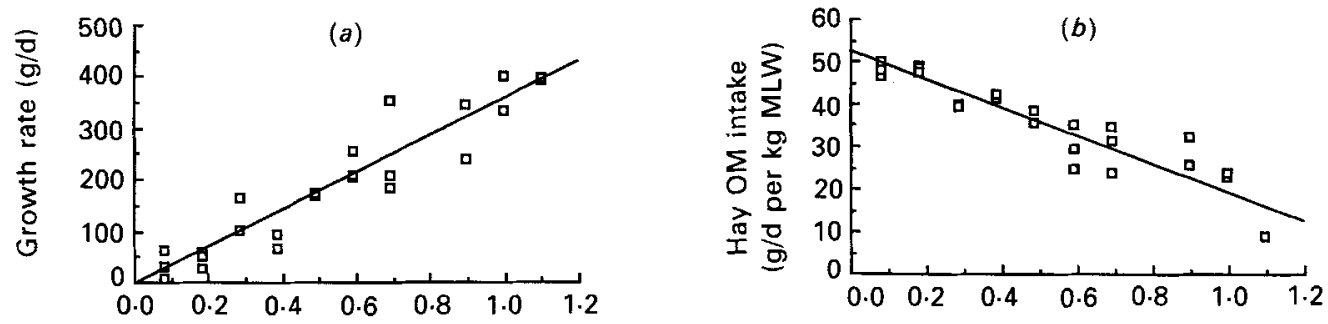

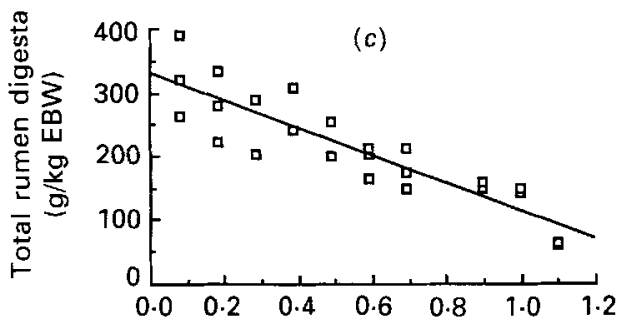

Total energy infused (MJ/d per kg MLW)

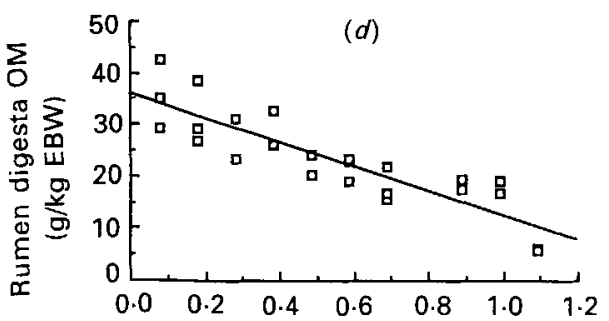

Total energy infused (MJ/d per $\mathrm{kg} \mathrm{MLW)}$

Fig. 1. The effect of total energy infused per unit metabolic live weight (MLW) on (a) the growth rates of lambs, (b) the organic matter (OM) intake per unit MLW from hay, (c) total rumen digesta per unit empty body-weight $(\mathrm{EBW})$ and $(d)$ rumen digesta $\mathrm{OM}$ per unit of EBW.

$$
\begin{aligned}
& \text { (a) } y=362.6 \text { (SE 27.4)x-5.31 (SE 17.20), }\left(r^{2} 0.88, P<0.001\right) \text {, } \\
& \text { (b) } y=52.25 \text { (SE 1.74)-33.00 (SE 2.77) } x, \quad\left(r^{2} 0.86, P<0.001\right) \text {, } \\
& \text { (c) } y=329.5 \text { (SE 15.3)-214.0 (SE 24.4)x, }\left(r^{2} 0.77, P<0.001\right) \text {, } \\
& \text { (d) } y=36.05 \text { (SE 1.73)-23.29 (SE 2.75)x, }\left(r^{2} 0.76, P<0.001\right) \text {. }
\end{aligned}
$$

Both the total amount of digesta and OM in the rumen declined with estimated NE intake, calculated from the equations of Black (1971). The relationship for total rumen digesta was:

$$
Y=345 \cdot 2(\operatorname{SE} 21 \cdot 5)-357 \cdot 7(\operatorname{SE} 53 \cdot 1) X, \quad r^{2} 0 \cdot 67,
$$

and for rumen digesta $\mathrm{OM}$ :

$$
Y=37.63\left(\text { SE 2.44) }-38.57\left(\text { SE 6.03) } X, \quad r^{2} 0.65,\right.\right.
$$

where $Y$ is either the total amount of digesta or $O M$ in the rumen $(\mathrm{g} / \mathrm{kg}$ rumen digesta-free, fleece-free live weight (RFFFLW) and $X$ is the estimated NE intake (MJ/d per $\mathrm{kg}$ RFFFLW ${ }^{0 \cdot 75}$ ).

OM intake from hay increased linearly with the amount of $\mathrm{OM}$ in the rumen (Fig. 2).

\section{Digestibility}

The estimated OM digestibility of the hay declined as the amount of nutrients infused increased (Table 2). The relationship was:

$$
Y=56.59 \text { (SE 1.56) - 11.91 (SE 2.48) } X, \quad r^{2} 0.51 \text {, }
$$

where $Y$ is the estimated $O M$ digestibility of the hay $(\%)$ and $X$ is the total energy infused (MJ/d per kg MLW). The estimated CWOM digestibility of hay did not change as the quantity of nutrients infused increased (Table 2). 


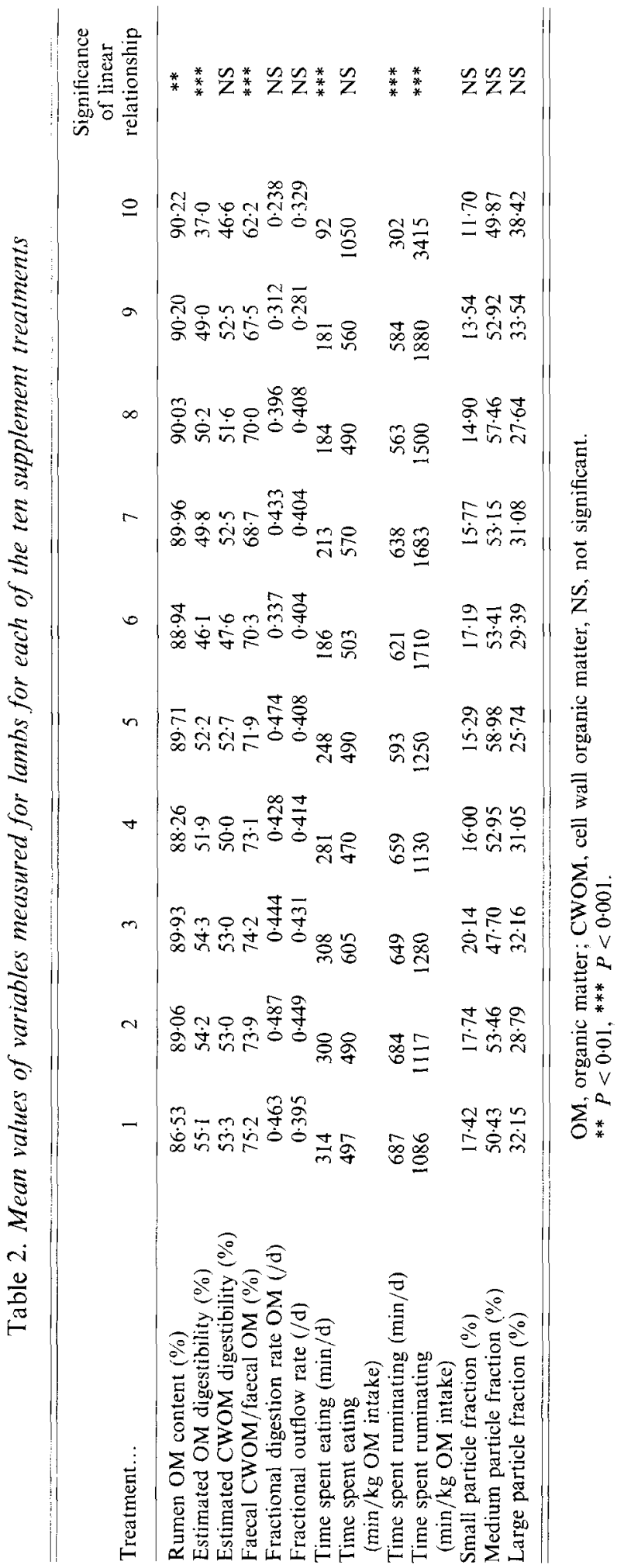




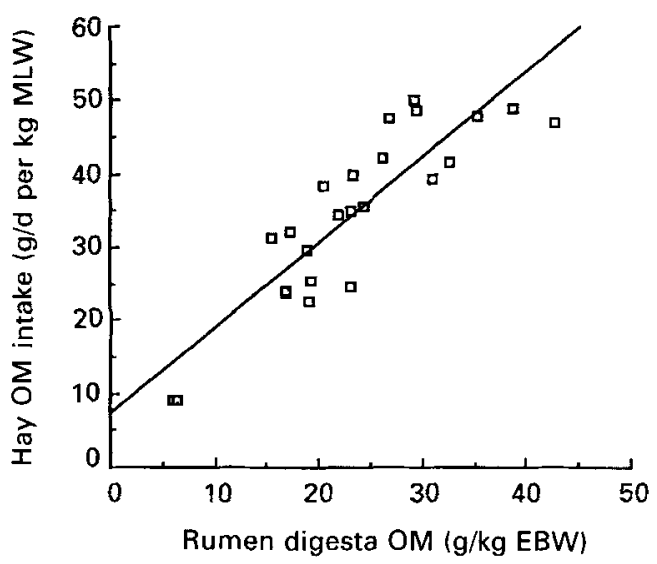

Fig. 2. The relation between organic matter (OM) intake from wheaten hay per unit metabolic live weight (live weight $\left.^{075}, \mathrm{MLW}\right), y$, and rumen digesta OM per unit empty body-weight (EBW), $x$, for lambs.

$$
y=7 \cdot 114(\operatorname{SE} 3 \cdot 460)+1 \cdot 165(\operatorname{SE} 0 \cdot 138) x, \quad\left(r^{2} 0 \cdot 75, P<0 \cdot 001\right) \text {. }
$$

Faecal CWOM as a proportion of total faecal OM declined as the amount of nutrients infused increased. The relationship was:

$$
Y=76 \cdot 37\left(\text { SE 1.26) }-10 \cdot 14 \text { (SE 2.00) } X, \quad r^{2} 0 \cdot 54,\right.
$$

where $Y$ is faecal CWOM as the proportion of faecal OM (\%) and $X$ is the total energy infused (MJ/d per $\mathrm{kg} \mathrm{MLW).} \mathrm{Accordingly,} \mathrm{as} \mathrm{faecal} \mathrm{non-CWOM} \mathrm{as} \mathrm{a} \mathrm{proportion} \mathrm{of} \mathrm{faecal}$ $\mathrm{OM}$ increased the quantity of nutrients infused increased.

\section{Rates of digestion and outflow}

Neither the fractional digestion rate of OM nor the fractional outflow rate of particulate matter from the rumen changed with the amount of nutrients supplied (Table 2). Similarly, there was no relationship between the OM intake of hay and either the fractional digestion rate of $\mathrm{OM}$ or the fractional outflow rate of particulate matter.

\section{Chewing behaviour}

The lambs spent less time eating per $\mathbf{d}$ as the quantity of nutrients infused increased (Table 2). The relationship was:

$$
Y=337 \cdot 4(\text { SE } 15 \cdot 0)-192 \cdot 0\left(\text { SE 23.8) } X, \quad r^{2} 0 \cdot 74,\right.
$$

where $Y$ is the time spent eating $(\mathrm{min} / \mathrm{d})$ and $X$ is the total energy infused $(\mathrm{MJ} / \mathrm{d}$ per $\mathrm{kg}$ MLW).

By contrast, the time spent eating per $\mathrm{kg} \mathrm{OM}$ intake was unaffected by the amount of nutrients infused from 0.8 to $1.0 \mathrm{MJ} / \mathrm{d}$ per $\mathrm{kg} \mathrm{MLW}$, but at the highest level of infusion $(1 \cdot 10 \mathrm{MJ} / \mathrm{d}$ per $\mathrm{kg} \mathrm{MLW})$ the lambs spent twice the amount of time eating per $\mathrm{kg} \mathrm{OM}$ intake (Table 2).

The time spent ruminating per $\mathrm{d}$ decreased linearly with the amount of nutrients infused (Table 2). The relationship was:

$$
Y=734.6(\mathrm{SE} 31 \cdot 9)-236 \cdot 2(\mathrm{SE} 50 \cdot 7) X, \quad r^{2} 0 \cdot 50,
$$


where $Y$ is the time spent ruminating (min/d) and $X$ is the total energy infused $(\mathrm{MJ} / \mathrm{d}$ per $\mathrm{kg} \mathrm{MLW).} \mathrm{At} \mathrm{the} \mathrm{highest} \mathrm{level} \mathrm{of} \mathrm{infusion,} \mathrm{the} \mathrm{time} \mathrm{spent} \mathrm{ruminating} \mathrm{per} \mathrm{day} \mathrm{declined}$ sharply relative to the other treatments. By comparison, the time spent ruminating per day increased with rumen $O M$ content. The relationship was:

$$
Y=389 \cdot 7(\operatorname{SE} 45 \cdot 6)+9 \cdot 26(\mathrm{SE} 1 \cdot 82) X, \quad r^{2} 0 \cdot 54
$$

where $Y$ is the time spent ruminating $(\mathrm{min} / \mathrm{d})$ and $X$ is the amount of rumen $\mathrm{OM}(\mathrm{g} / \mathrm{kg}$ EBW).

The time spent ruminating per $\mathrm{kg} O M$ intake increased with the quantity of nutrients infused (Table 2). The relationship was:

$$
Y=768 \cdot 6(\operatorname{SE} 169 \cdot 0)+1494(\operatorname{SE} 269) X, \quad r^{2} 0 \cdot 58,
$$

where $Y$ is the time spent ruminating ( $\mathrm{min} / \mathrm{kg}$ OM intake) and $X$ is the total energy infused $(\mathrm{MJ} / \mathrm{d}$ per $\mathrm{kg} \mathrm{MLW})$. By contrast, the time spent ruminating per $\mathrm{kg} O \mathrm{OM}$ intake declined as the $O M$ intake from hay increased. The relationship was:

$$
Y=3273\left(\text { SE 192) }-49 \cdot 28\left(\operatorname{SE~5\cdot 27)~} X, \quad r^{2} 0 \cdot 80,\right.\right.
$$

where $Y$ is the time spent ruminating ( $\mathrm{min} / \mathrm{kg} \mathrm{OM}$ intake) and $X$ is the OM intake from hay (g/d per kg MLW).

\section{Particle size distribution}

There was no significant difference in the proportion of particles present in the small (particles passing through a sieve of pore size $0.15 \mathrm{~mm}$ ), medium (particles passing through a sieve of pore size $1.18 \mathrm{~mm}$ and retained on sieve of pore size $0.15 \mathrm{~mm}$ ) and large (particles retained on sieve of pore size $1.18 \mathrm{~mm}$ ) particle fractions in the rumen, as the amount of nutrients infused increased (Table 2). The proportion of particles present in these fractions did not change with the amount of DM present in the rumen.

\section{DISCUSSION}

The growth rate of the lambs increased as the amount of nutrients infused increased, demonstrating that the energy available from the hay was not substituted for nutrients infused on a direct energy basis. If there had been a direct substitution of energy, the lambs would have grown at a constant rate.

Rumen digesta load declined as the quantity of nutrients infused increased, suggesting that rumen digesta load increases as the gap between nutrient supply and demand (i.e. energy deficit) increases. The increase in rumen digesta load was paralleled by an increase in the intake of hay, as the lambs attempted to increase their total energy intake and bridge the gap between energy supply and demand.

Both the total amount of digesta and $O M$ in the rumen were found to be inversely related to the estimated NE intake of the ram lambs. This finding is similar to that observed by Weston (1984) for wether weaners with different capacities for utilizing energy and fed on a range of roughage diets. The results of this study are compared in Fig. 3( $a$ and $b)$ with those of wether weaners fed on a range of forages: alkali-treated straw (Davis \& Weston, 1986), roughages (Weston, 1984), roughage plus concentrate (Weston, 1988) and wheaten straw plus lucerne hay (Weston \& Davis, 1986). They are compared in relation to estimated $\mathrm{ME}$ intake because of the difficulty in accurately predicting NE intake across roughage and liquid diets. At the same level of estimated ME intake, the ram lambs had a higher amount of total digesta and $\mathrm{OM}$ in the rumen than the wethers, which may indicate that the ram lambs have the greater capacity for utilizing energy. The difference may also be due to the 

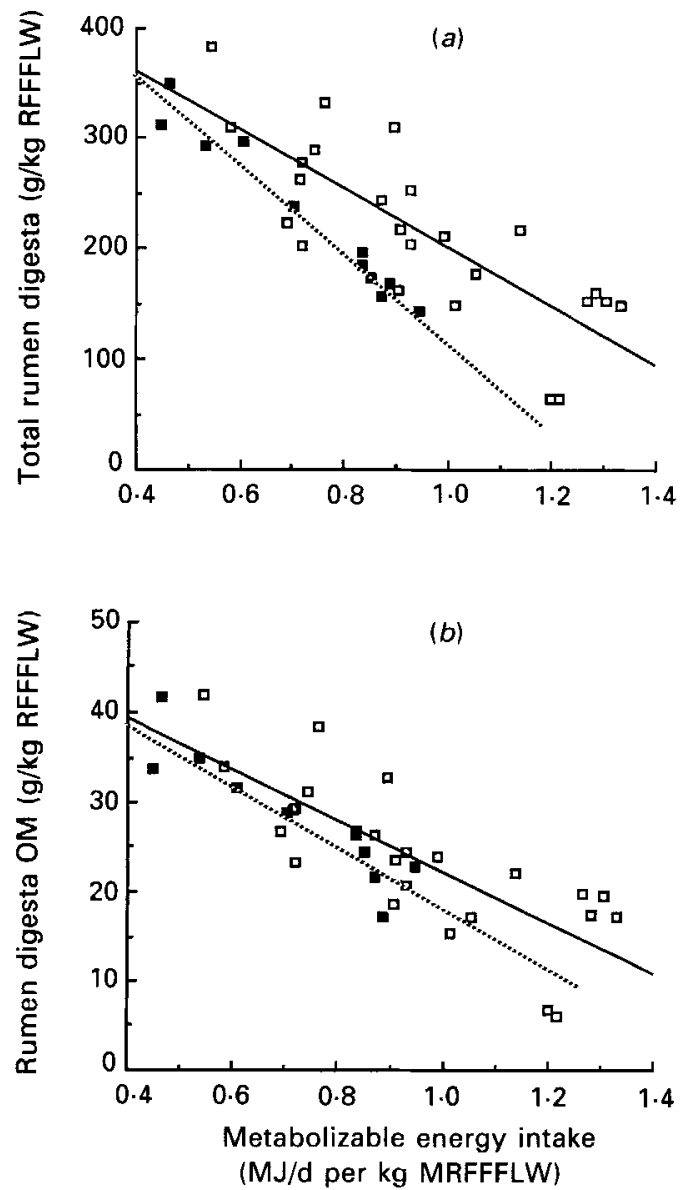

Fig. 3. The effect of metabolizable energy intake per unit metabolic rumen digesta-free, fleece-free live weight (MRFFFLW) on: (a) total rumen digesta per unit rumen digesta-free, fleece-free live weight (RFFFLW); (b) rumen digesta organic matter (OM) per unit RFFFLW. Plots of present experiment values ( $\square-\cdots$ - $\square$ ) are compared with those of Davis \& Weston (1986), Weston (1984), Weston (1988) and Weston \& Davis (1986) (드...

(a) $y=466 \cdot 1\left(\right.$ SE 42.0) $-265 \cdot 4$ (SE 43.2)x, $\quad\left(r^{2} 0 \cdot 63, P<0 \cdot 001\right)$ (present experiment) $y=512.1$ (SE 18.7) $-391.4(\mathrm{SE} 25 \cdot 1) x, \quad\left(r^{2} 0.96, P<0.001\right)$ (published results)

(b) $y=50.65$ (SE 4.75) - 28.60 (SE 4.88)x, $\left(r^{2} 0.61, P<0.001\right)$ (present experiment) $y=53.44($ SE 3.86$)-34.85(\operatorname{SE} 5.17) x, \quad\left(r^{2} 0.82, P<0.001\right)$ (published results)

type of roughage offered, as the ram lambs were offered a low to medium quality wheaten hay, whereas the wethers were offered diets ranging from low to medium quality roughages through to a roughage plus concentrates.

The difference in the total amount of rumen digesta between the ram lambs and the wethers increased with ME intake. This difference was less apparent for the amount of rumen OM than for total rumen digesta, which was explained, in part, by the decrease in $\mathrm{OM}$ as a proportion of DM present in the rumen of the ram lambs at the higher energy intakes. The decrease in $O M$ as a proportion of DM present in the rumen was positively related to the decrease in the $\mathrm{OM}$ intake by the ram lambs (see Fig. 1 $(b)$ and Table 2).

There was a positive, linear relationship between the amount of $O M$ in the rumen and the $\mathrm{OM}$ intake of roughage by the ram lambs. By comparison, there was no significant 
relationship between $O M$ intake and either the fractional digestion rate of $O M$ or the fractional outflow rate of particulate matter from the rumen. Accordingly, the intake of roughage in this study was limited primarily by the rumen digesta load of the ram lambs. Weston \& Cantle $(1982,1983)$ explained the differences in intake between sheep in different physiological states or of different genotypes primarily by differences in the rumen digesta loads of the animals. The findings from these studies support the predictions of Black et al. (1982) which showed that rumen digesta load can markedly affect the intake of roughage by sheep.

The time spent ruminating increased with the amount of $O M$ in the rumen, reaching a maximum at about $12 \mathrm{~h} / \mathrm{d}$, which is similar to the maximum ruminating time previously reported in the literature of $12.6 \mathrm{~h} / \mathrm{d}$ (Weston, 1984). Thus, the lambs with the highest digesta loads spent more time ruminating per day to aid the breakdown and clearance of digesta from the rumen, a result similar to that reported by Ulyatt (1983). However, the time spent ruminating per $\mathrm{kg} \mathrm{OM}$ intake declined as intake increased. It is possible that either rumination became more efficient in reducing particle size at the higher intakes, or larger particles were able to escape from the rumen. The proportion of particles retained on the $1.18 \mathrm{~mm}$ sieve, which is about the critical size for escaping the rumen (Poppi et al. 1980), did not decline significantly as rumen DM load increased, which suggests that the time spent ruminating was used more efficiently. The studies of Welch \& Smith (1969) and Faichney (1986) support this contention. They found that the time spent ruminating per $\mathrm{kg}$ DM intake declined as the intake of hay by sheep increased.

The estimated OM digestibility of hay declined as the quantity of nutrients infused increased, whereas the estimated digestibility of CWOM remained the same. The higher proportion of non-CWOM present in the faecal OM of the lambs receiving the higher energy supplements contributed to the lower OM digestibility of hay. The increase in faecal non-CWOM with increasing infusion of the liquid supplement may have resulted from greater microbial activity in the large intestine and hence an increase in microbial OM in the faeces.

The results from the present study have defined an inverse relationship between rumen digesta load and net energy intake for lambs with similar capacities for utilizing energy and offered a single roughage diet. The definition of this relationship will provide quantitative information that can be used in the development of equations for predicting voluntary feed intake by sheep. It was of interest that an absolute upper limit to rumen digesta load was not achieved despite the growth rates of the lambs being reduced from about 400 to $34 \mathrm{~g} / \mathrm{d}$. At the lowest growth rate, that is, at the highest energy deficit, the mean upper limit to rumen digesta load of $35.6 \mathrm{~g} \mathrm{DM} / \mathrm{kg}$ rumen digesta-free body-weight (RFBW) was similar to the rumen digesta load reported by Weston (1985) for weaners offered a ryegrass (Lolium perenne) hay (34.8 g DM/kg RFBW) (Weston, 1984). However, the value of $35.6 \mathrm{~g} \mathrm{DM} / \mathrm{kg}$ RFBW was $25 \%$ lower than the previous highest value reported in the literature of $44.7 \mathrm{~g} \mathrm{DM} / \mathrm{kg} \mathrm{RFBW}$ (Weston, 1985) for weaners offered a straw plus concentrate $(85: 15$ $w / w$ ) diet (Weston, 1980). An absolute upper limit to rumen digesta load may have been observed in the present study if a poorer quality roughage had been used.

S. G.G. was supported by a Wool Research Trust Fund Postgraduate Scholarship on the recommendation of the Australian Wool Corporation. The authors wish to thank Messrs W. F. Colebrook and K. J. James for their assistance throughout the experiment and Mrs P. Cummings for the fibre analyses. They acknowledge Mr J. B. Donnelly for his advice in the initial designing of the experiment and Dr G. J. Faichney for his comments on the draft manuscript. 


\section{REFERENCES}

Agricultural Research Council (1965). The Nutrient Requirements of Livestock no. 2, Ruminants. London: Agricultural Research Council.

Agricultural Research Council (1980). The Nutrient Requirements of Farm Livestock. Farnham Royal: Commonwealth Agricultural Bureaux.

Black, J. L. (1971). A theoretical consideration of the effect of preventing rumen fermentation on the efficiency of utilization of dietary energy and protein in lambs. British Journal of Nutrition 25, 31-55.

Black, J. L. (1984). The integration of data for prediction of feed intake, nutrient requirements and animal performance. In Herbivore Nutrition in the Subtropics and Tropics, pp. 648-671 [F. M. C. Gilchrist and R. I. Mackie, editors]. Graighall: Science Press.

Black, J. L., Faichney, G. J. \& Sinclair, R. E. (1982). Role of computer simulation in overcoming limitations to animal production from pastures. In Nutritional Limits to Animal Production from Pastures, pp. 473-493 [J. B. Hacker, editor]. Farnham Royal: Commonwealth Agricultural Bureaux.

Black, J. L. \& Griffiths, D. A. (1975). Effects of live weight and energy intake on nitrogen balance and total N requirements of lambs. British Journal of Nutrition 33, 399-413.

Colebrook, W. F. \& Black, J. L. (1981). Influence of dietary lysine content on energy utilization in pre-ruminant lambs. Animal Production 33, 253-258.

Davis, P. \& Weston, R. H. (1986). The effect of alkali treatment of wheaten straw on palatability, feed intake and various aspects of digestion with sheep. Proceedings of the Nutrition Society of Australia 11, 168-171.

Faichney, G. J. (1980). Measurement in sheep of the quantity and composition of rumen digesta and of the fractional outflow rates of digesta constituents. Australian Journal of Agricultural Research 31, 1129-1137.

Faichney, G. J. (1986). The kinetics of particulate matter in the rumen. In Control of Digestion and Metabolism in Ruminants, pp. 173-195 [L. P. Milligan, W. L. Grovum and A. Dobson, editors]. New Jersey: Prentice Hall.

Faichney, G. J. \& White, G. A. (1983). Methods for the Analysis of Feeds Eaten by Ruminants. Melbourne: CSIRO.

Gherardi, S. G., Black, J. L. \& Kellaway, R. C. (1985). Influence of nutrient deficit on rumen content and voluntary intake of roughage by sheep. Proceedings of the Nutrition Society of Australia 10, 143.

Neilsen, M. J. \& Richards, G. N. (1978). The fate of the soluble lignin-carbohydrate complex produced in the bovine rumen. Journal of the Science of Food and Agriculture 29, 513-519.

Neutze, S. A. (1985). Kinetics of nitrogen transfer across the rumen wall of sheep. MSc Thesis, University of Sydney, Australia.

Poppi, D. P., Norton, B. W., Minson, D. J. \& Hendrickson, R. E. (1980). The validity of the critical size theory for particles leaving the rumen. Journal of Agricultural Science, Cambridge 94, 275-280.

Ulyatt, M. J. (1983). Plant fibre and regulation of digestion in the ruminant. In Fibre in Human and Animal Nutrition, pp. 103-107 [G. Wallace and L. Bell, editors]. Wellington: The Royal Society of New Zealand.

Welch, J. G. \& Smith, A. M. (1969). Effect of varying amounts of forage intake on rumination. Journal of Animal Science 28, 827-830.

Weston, R. H. (1980). Roughage intake and digestion comparisons with lambs and adult sheep. Proceedings of the Nutrition Society of Australia 5, 191 .

Weston, R. H. (1984). Rumen digesta load in relation to the voluntary feed consumption and rumination in roughage-fed young sheep. Canadian Journal of Animal Science 64, Suppl., 324-325.

Weston, R. H. (1985). The regulation of feed intake in herbage-fed young sheep. Proceedings of the Nutrition Society of Australia 10, $55-62$.

Weston, R. H. (1988). Factors limiting the intake of feed by sheep. X. The effect of concentrate supplements on the voluntary consumption and digestion of a medium quality roughage. Australian Journal of Agricultural Research 39, 255-271.

Weston, R. H. \& Cantle, J.A. (1982). Voluntary roughage consumption in growing and lactating sheep. Proceedings of the Nutrition Society of Australia 7, 147.

Weston, R. H. \& Cantle, J. A. (1983). Digestion studies with two sheep genotypes exhibiting a difference in voluntary roughage consumption. Proceedings of the Nutrition Society of Australia 8, 177-180.

Weston, R. H. \& Davis, P. (1986). Low palatability as a constraint to the intake of wheaten straw diet by sheep. Proceedings of the Nutrition Society of Australia 11, 172-175. 